ИСТОРИЯ ЯЗЫКА, ФИЛОСОФИЯ ЯЗЫКА, ЯЗЫКОВАЯ КАРТИНА МИРА

https://doi.org/10.31912/pvrli-2020.2.13

\author{
E. Э. Бабаева \\ МГУ им. М. В. Ломоносова \\ (Россия, Москва) \\ llevidova@gmail.com
}

\title{
ОБ ОДНОЙ ОСОБЕННОСТИ СИСТЕМЫ ПРЕДИКАТОВ ПОЛОЖЕНИЯ В ПРОСТРАНСТВЕ ВО ФРАНЦУЗСКОМ ЯЗЫКЕ
}

В статье на основе анализа французских филологических источников XVIXVII вв. предлагается гипотеза относительно контекстных условий появления и закрепления в системе позиционных глаголов французского языка предиката être debout, а также относительно хронологии этого процесса. Позиционные глаголы ('стоять', 'сидеть', 'лежать'), прототипически указывающие на позу человека, выделяются внутри более широкой группы предикатов местоположения. Позиционные глаголы входят в 200-словный список Сводеша (Swadesh list), который объединяет единицы, относящиеся к наиболее устойчивому базовому словарю языка. В романских языках смысл 'стоять' может передаваться несколькими способами, например глаголом stare, восходящим в конечном итоге к и.-е. *st $\bar{\alpha}-$ : sta- (ит. stare, румын. sta), а также рядом словосочетаний, например: 'стоять на ногах' (ит. stare in piedi, исп. estar di pie, порт. estar de pié, румын. sta pe picioare), 'быть на ногах' (ит. essere in piedi), 'находиться на ногах' (ит. rimanere in piedi, порт. ficar de pé), 'быть прямым' (ит. essere ritto, катал. estar dret). Особенностью французского языка является передача смысла 'стоять' при помощи предиката être debout, который вытеснил древний глагол ester. В статье высказывается гипотеза, согласно которой предикат être debout, сформировавшийся в XIV в., получает особое распространение в XVI в. При интерпретации этого процесса нельзя не учитывать факт паронимической аттракции между позиционным глаголом ester и глаголом существования estre, которая создавала большие неудобства. Однако усиление позиций предиката être debout стало возможным, вероятно, благодаря грамматико-семантическому фактору: императив Debout, являвшийся в то время, по всей вероятности, инновацией, позволил аккумулировать представление о переходе от горизонтального положения к вертикальному и одновременно — от пассивного состояния

* Работа выполнена при финансовой поддержке РФФИ в рамках проекта №19-012-00291 (Подготовка Активного словаря русского языка). 
к активному, что и привело к закреплению именно этого предиката в системе позиционных глаголов.

Ключевые слова: историческая семантика, история лексикографии, история понятий, история словарного фонда, функциональная грамматика.

Как хорошо известно, в рамках теории функциональной грамматики под глаголами положения в пространстве понимаются глаголы, которые требуют в качестве актанта или же допускают при себе различные единицы, выражающие местонахождение объекта [Гак 1996: 13]. В языках принято различать универсальную и классифицирующую тенденцию при обозначении местонахождения - в зависимости от того, связан ли выбор предиката с тем, к какому семантическому классу принадлежит субъект местонахождения [Рахилина 1998: 68]. В рамках данного типа предикатов выделяются так называемые глаголы положения в пространстве (ср. также использующиеся исследователями другие термины: позиционные предикаmы, позиционные глаголь; глаголь позиции, stance verbs, orienational verbs, verbs of position, posture verbs, postural verbs, posturals, positional verbs, verbes de position dans l'espace, verbes de posture, verbes positionnels, Verben der Position), обозначающие 'стоять', 'сидеть', 'лежать', которые прототипически описывают позу человека. Согласно Ю.Д. Апресяну, для таких глаголов характерно обнаружение «на определенном шаге семантической реконструкции в вершине ассерции» смысла ‘быть расположенным как-то’ [Апресян 2010: 293] ${ }^{1}$. Среди предикатов положения в пространстве применительно к описанию положения тела человека могут выделяться стандартные и нестандартные глаголы [Дмитренко, Храковский 2011: 187; 2013; Корди 2016]; см. также рассмотрение глаголов нестандартных положений тела ${ }^{2}$ и перехода тела в нестандартные положения во французском языке в [Корди 2014; 2015].

Позиционные предикаты в их соотношении со смыслами нахождения и существования, а также процессы их грамматикализации активно изучаются в теоретической и типологической перспективах [см., например: Ameka, Levinson 2007; Grinevald 2005; Hansen 1974; Jakobsson 1996; Kuteva 1999; Newman 2002; Serra Borneto 1996; Van der Toorn 1972; Van Oosten 1982; Аошуан 2004: 13-20; Кашкин 2016а; 2016б; Кюсева, Рыжова 2013; Майсак 2005; Рахилина, Лемменс 2003; Стоянова 2013].

Согласно общепринятому мнению, смыслы ‘стоять', ‘сидеть', ‘лежать' относятся к «универсалиям жизненного опыта», хотя в языках не всегда имеются специальные лексемы для выражения этих смыслов [Майсак 2005: 122, 126]. Глаголы, имеющие данную семантику, входят в 200-словный список базовой лексики Морриса Сводеша (Swadesh list). В относительно недавно появившемся списке ЛейпцигДжакарта смысл 'стоять' находится на 45 месте по семантической стабильности,

${ }^{1}$ Ю.Д. Апресян включает в данный класс не только прототипические глаголы положения в пространстве, но и их синонимы [Апресян 2006: 87].

2 В частности, особого наклонного положения тела; ср. еще предикат со значением 'висеть'. 
при этом интересно, что значения 'сидеть' и 'лежать' в этот список вообще не вошли [Tadmor et al. 2010: 239]. Исследователями отмечалось, что типологически из всех глаголов положения в пространстве наиболее «активным» является именно глагол, обозначающий 'стоять'. «Прочтение» этого смысла как функционального представлено в современных языках; ср., например, приведенные Т.А. Майсаком данные папуасских языков, в которых мужчина всегда будет описываться как стоящий, вне зависимости от его реальной позы, поскольку он всегда активен, сражается или рубит деревья [см. об этом подробнее: Майсак 2005: 130-132].

Индоевропейский корень $s t \bar{a}-,{ }^{*} s t \partial-,{ }^{*} s t e h_{2}-,{ }^{*} s t a h_{2}-$, как хорошо известно, лежит в основе огромной системы понятий; см., например, обширный перечень рефлексов в индоевропейских языках в [IGW]. В. Н. Топоров, посвятивший смыслу предиката со значением 'стоять' специальную работу, относит его к ключевым словам ${ }^{3}$, некогда составлявшим «языковой и понятийный каркас как космологических, так и антропологических текстов» [Топоров 1996: 27].

В романских языках смысл 'стоять' может передаваться как глаголами, восходящими к индоевропейскому корню (например, ит. stare, румын. sta), так и некоторыми глагольными сочетаниями, в частности с бытийными глаголами:

1) 'стоять на ногах’: ит. stare in piedi, исп. estar di pie, порт. estar de pié, румын. sta pe picioare;

2) 'находиться на ногах': ит. rimanere in piedi; порт. ficar de pé;

3) 'быть на ногах’: ит. essere in piedi;

4) 'стоять прямо': ит. essere ritto; катал. estar dret.

В данных сочетаниях можно видеть представленность двух основных идей: опоры на ноги и вертикальной ориентации. На этом фоне французский язык, в котором существуют предикаты être <se tenir> debout ('быть <держаться> стоя'), с точки зрения того, как выражается в данных предикатах представление о вертикальном положении, является особым случаем. Между тем, насколько мне известно, не существует работ, в которых объяснялся бы механизм появления и распространения во французском языке глагольных словосочетаний, указывающих на вертикальное положение субъекта, включающих наречие debout.

Хорошо известно, что современная парадигма французского глагола être в диахроническом плане представляет собой результат развития трех глагольных основ ${ }^{4}$. Прежде всего следует упомянуть использовавшийся в народной латыни глагол essere, восходящий к лат. esse (и.-е. *es-, для которого выделяются значения 'существовать', 'расти', 'цвести' [см.: IGW]). Аористная основа $f u$ - восходит к ин-

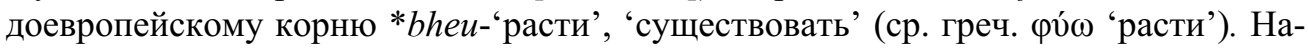
конец, причастные формы (été, étant) заимствованы у старофранцузского глагола

${ }^{3}$ Согласно В.Н. Топорову, ключевые элементы всегда отсылают «за пределы языка и потому дают основания для суждений и о внеязыковых мотивировках языковых фактов» [Топоров 2006: 129].

${ }^{4}$ Из-за этой особенности он даже мог рассматриваться как «курьез» (une curiosité) [см.: Thomasson 1938: 10-11]. 
ester ('стоять'), соответствовавшего лат. stare. Таким образом, семантика глагола être связана с тремя идеями: существование, рост и вертикальное положение.

C самых первых фиксаций глагол être, употребляясь как полнозначный глагол и как связка, мог указывать, в частности, на существование и состояние субъекта. Первые же фиксации глагола ester ('стоять') датируются XII в. Согласно данным «Dictionnaire du Moyen français» [DMF], в текстах XIII-XV вв. активно используются коллокации droit et estant ('прямо и стоя'), estant ou assis ('стоя или сидя').

Глагол ester, используясь применительно к человеку, имел в средневековом французском различные употребления:

1) указывал на то, что человек занимает определенное положение в пространстве, а именно - что он стоит, а не сидит и не лежит, ср., например: Un homme a ensemble la vertu ou puissance de soy seoir et de soy ester (Nicole Oresme, Le Livre $\mathrm{du}$ ciel et du monde, 1377) ${ }^{5}$. Употребляясь таким образом, он мог сочетаться с названием опоры - ester sur pieds, см., например: Quel cose faisons nous chi, estans sus nos piés et nous refroidant? (Jean Froissart, Chroniques, 1369);

2) указывал на фиксированное положение человека, иначе говоря, на отсутствие или прекращение движения, ср., например: Puis prent son coutel de quoy il trenche et frappe dessus la table, puis s'en va ou jardin, puis revient et ne peut ester ne fere contenance (Les quinze joies de mariage, 1464), ср. также приказ остановиться Esta! Употребляясь в предложной конструкции ester de, указывал на прекращение действия, названного инфинитивом: Elle dist qu'elle n'avoit qu'ester de cheminer (Perceforest, XIV);

3) наконец, указывал не просто на вертикально ориентированное положение человека с опорой на ноги, но и на его особое внутреннее состояние, мобилизацию ресурсов, готовность к важному событию, к действию, ср., например: a ce que vous puissiez resister et ester contre les agaiz de l'anemi (Miracle de Saint Valentin, XV). Можно привести также устойчивые словосочетания estera dreit, ester en droit, ester en jugement (ср. pус. предстать перед судом, а также совр. франц. ester en jugement $<$ en justice> 'участвовать в судебном процессе'), входившие в юридический словарь в соответствии с юридическими употреблениями лат. stare. На особую роль нахождения в вертикальном положении для переживания некоторых особо отмеченных ситуаций могут указывать такие, например, русские словосочетания, как стоять на молитве, стоять перед Богом, стоять за правду, стоять насмерть [см. также: Бабаева 2006: 799-800].

Estant, причастие от глагола ester, может указывать собственно на вертикальное положение человека: être en (son) estant, être <se tenir> sur son estant; Messires Jehans Chandos, pour la dolour qu'il senti, ne se peut tenir en estant, mès chei à terre (Jean Froissart, Chroniques, 1369); cp. также l'estant d'un homme (о росте человека), un estant 'вертикальное положение', soi relever en estance 'встать', en (son) estage 'вертикально', un estage 'рост человека' [FEW 12: 237-243]. Однако в XIV в.

5 Здесь и далее примеры, относящиеся к средневековому французскому, взяты из словаря [DMF]. 
со словосочетаниями être en (son) estant, être <se tenir> sur son estant вступают в конкуренцию другие: être $<$ se tenir $>$ debout.

Слово debout, функционировавшее как существительное и как наречие, является производным от существительного bout, восходящего, в свою очередь, к глаголу bouter. Глагол bouter, присутствующий уже в текстах XI в., примерно к XVII-XVIII вв. практически вышел из употребления. Он является заимствовани-

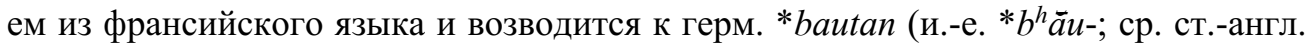
beaten, ст.-норв. bauta, ст.-в.-нем. bozan). Согласно [FEW], изначальная семантика глагола bouter была связана с представлением об ударе, и ее можно реконструировать примерно как 'толкать', 'ударять' (ср. в древне- и средневековом французском un but 'удар', une boutée ‘удар', 'толчок', 'атака' или же выражение d'une boutée 'одним ударом’). В текстах XII в. зафиксированы также префиксальные глаголы rebouter и débouter, которые также имеют семантику агрессии - как нападения, так и обороны: ‘ударять', 'атаковать', ‘отражать удар', ‘делать так, чтобы кто-л. отступил (в бою)'.

Смысл 'ударять' имеет большой семантический потенциал, на что указывает, кстати, и развитие огромной многозначности существительного соир 'удар'. Постепенно глагол bouter развивает «растительную» семантику: он начинает употребляться в значениях 'расти', 'набухать' (ср. семантическую эволюцию глагола pousser: 'толкать' $\rightarrow$ 'прорастать из земли'). Отглагольное имя bout употребляется применительно к разным - преимущественно вытянутым - объектам, обозначая конечную часть. C XIV в. в таком же значении могло использоваться существительное debout (< de bout), применяясь, например, к копью, мосту, кораблю, реке, стране [DMF]. При этом вытянутый объект мог иметь как вертикальное, так и горизонтальное расположение. В случае вертикальной ориентации объекта его конечная часть интерпретируется как верх. C XV в. в текстах фиксируется наречие debout 'в конце' $\rightarrow$ 'вертикально', а предикат être debout начинает указывать на вертикальную ориентацию объекта, в том числе и позу человека; ср. использование во французской поэзии колоса как прототипа такой ориентации: Prince, si j'eusse eu la pepie, / Pieça je fusse où est Clotaire, / Aux champs debout comme une espie (François Villon, Ballade de l'appel, 1456-1463); Estoit-il lors temps de me taire? Je ne suis point des excessifs / Importuns, carj'ai la pépie, / Dont suis au venc comme un châssis / Et debout ainsi qu'une espie (Clément Marot, A Madame d'Aleçon Marguerite de Valois, 1518).

Таким образом, к XVI в. возникает синонимия предикатов être en son estant и être debout. Кроме того, в текстах появляются новые глагольные сочетания: (se) mettre debout, se lever debout. Тем не менее причастие estant в XV в. остается попрежнему употребительным.

Ситуация меняется в XVI в. Робер Этьенн (Robert Estienne), французский лексикограф и типограф, автор французско-латинского словаря («Dictionnaire françoislatin, contenant les motz et les manières de parler françois, tournez en latin»), опубликованного в 1539 г., включает в словник выражения estre, se tenir debout sur ses pieds, не упоминая при этом словосочетания être en son estant: «Debout. Estre ou 
se tenir debout sur les pieds. Stare. On est ici debout sans rien faire» [Estienne 1539: 130]. В более позднем словаре «Dictionnarium latinogallicum» (1552) Робер Этьенн использует для перевода латинского stare как сочетание estre debout sur ses pieds, так и estre en son estant как синонимичные, помещая, однако, последнее на второе место [Estienne 1552: 420]. Цезарь Уден (Cesar Oudin), составивший испано-французский словарь («Thresor des deux langues», 1575), переводит estar en pie как estre debout, se tenir sur ses pieds [Oudin 1575: 523].

В словаре французского языка Жана Нико (Jean Nicot) «Thresor de la langue francoyse tant ancienne que moderne» (1606) основным средством выражения смысла 'стоять' (лат. stare) также признаются выражения estre, se tenir debout sur ses pieds, в то время как estant соотносится с quum essem [Nicot 1606: 177]. Вместе с тем Жан Нико не исключает возможности использования причастия estant в coответствии с erectus: «Se dresser en estant, c'est se dresser sur pieds et debout. On dit aussi, En son estant droict sur pieds» ${ }^{6}$ [Там же: 177].

Очевидно, что предикат estre en son estant начиная с XVI в. постепенно стал отодвигаться на периферию узуса, уступая место выражениям estre $<$ se tenir $>$ debout.

Существует текст, который, как мне кажется, позволяет предположить, какой фактор определил смену предикатов со значением 'стоять'. Речь идет о книге «L'éclaircissement de la langue française» (1530), написанной Джоном Палсгрейвом (John Palsgrave) ${ }^{7}$, английским лингвистом, современником Робера Этьенна, которая считается первым учебником французского языка для иностранцев. В книге Джона Палсгрейва описано несколько контекстов, включающих слово debout.

1. Указание на вертикальное положение человека с опорой на ноги. Согласно Паслсгрейву, в этом случае используется предикат être debout: «I am afoot, I stand upon my foot. Je suis debout» [Palsgrave 2003: 422].

2. Указание на прекращение болезненного состояния, плохого самочувствия, из-за которого человек вынужден лежать. И в этом случае предпочтение отдается предикату être debout: «lacouché de cy pres est elle encore [déjà] debout? (Is this woman that lay a chylde bedde here be a foots agayne)» [Palsgrave 2003: 422]. В данном случае речь идет, таким образом, об осмыслении вертикального положения как активного начала, противопоставленного пассивному, горизонтальному (ср. pус. восстать после болезни <из мертвых>; быть на ногах) ${ }^{8}$. Представление о том, что выражение être debout передает идею выздоровления, воспроизводится позже Антуаном Фюретьером (Antoine Furetière) в его труде «Dictionnaire universel» (1690): «cet homme a été logtemps alitté, mais maintenant il est debout» [Furetière 1: 603]. Точно так же и «Dictionnaire de l'Académie française» (1694) перефразирует высказывание Il est debout как Il se porte mieux [DAF 1: 123].

${ }^{6}$ Интересно, что форма en son estant признается противопоставленной форме en son seant.

7 Джон Палсгрейв в юности учился в Париже. Позже он стал наставником принцессы Марии Тюдор, впоследствии вышедшей замуж за Людовика XII, и обучал ее французскому языку.

${ }^{8}$ Cp. orientational methaphors в терминах Дж. Лакоффа и Марка Джонсона: «GOOD IS UP gives an UP orientation to general well-being, and this orientation is coherent with special cases like HAPPY IS UP, HEALTH IS UP, ALIVE IS UP» [Lakoff, Johnson 2003: 18] 
3. Указание на переход из лежачего положения в вертикальное как смена позиции: «I aryse upon my fete, as a man do the that lueth alonge on the grounde, or that is felled to the grounde» [Palsgrave 2003: 692]. Данную ситуацию, как полагает Палсгрейв, могут обслуживать предикаты se lever debout и se dresser sur son estant. Вместе с тем он, по-видимому, считает выражение se dresser sur son estant стилистически не нейтральным, более редким, поскольку вводит его со следующим комментарием: «J fynde also used in the same sensje madresse sur mon estant». Из этого следует, что в первой четверти XVI в. еще были люди, использовавшие данный предикат в речи.

4. Императив. Палсгрейв указывает, что быстрый переход из лежачего положения в вертикальное может быть описан обоими предикатами: «Не rose up on his fete quyckly: il se lieua debout vistement, or il se adressa sur son estant vistement» [Palsgrave 2003: 692]. Однако в императиве, которому, как полагал Палсгрейв, бывают присущи агрессивность и отрывистость («whan it is spokyn to an enemy or in haste»), используется debout с опущением глагола: «they saye debout only and live out the verbe» [Там же: 732]. Согласно [DMF], первые фиксации данного императива относятся к рубежу XV-XVI вв.; заметим также, что они отмечены в комедийном жанре соти.

Императив Debout! выражает не только приказ встать, но и - синкретично призыв к началу действия (ср. известное начало гимна Эжена Потье: Debout! les damnés de la terre! / Debout! les forçats de la faim!). Появление таких употреблений, несомненно, давало большое преимущество предикатам, включавшим наречие debout.

Форма императива Debout!, по всей видимости, была инновацией, во всяком случае, она лексикографируется филологами XVII в. Так, Филибер Моне (Philibert Monet) в словаре «Invantaire de deux langues francoise et latine» (1635) пишет: «Debout, mot excitatif à se mettre sur pied, se lever sur debout, qu'on se leue [:Ë̈a, agite, surgite, erigite vos in pedes, ad operam accingite]» [Monet 1635: 273]. Другой лексикограф, Франсуа-Антуан Помей (François-Antoine Pomey), также помещает данный императив в словарь «Dictionnaire royal» (1671): «Debout Leve toi» [Pomey 1671: 260]. Антуан Фюретьер подчеркивает: «Quand on éveille quelqu'un à la haste, on luy crie, Debout, debout; fut debout, il est grand jour» [Furetière 1: 603]. Наконец, в первом издании «Словаря Французской академии» указывается: «Absolument, Debout, pour dire Levez-vous» [DAF 1: 123].

Как полагал Э. Бенвенист, чтобы понять, каким образом произошел скачок в семантическом развитии слова, следует найти тот контекст, который потенциально скрывал в себе возможность разрыва9. Цель данной работы состояла в том, чтобы, проанализировав корпус средневековых французских контекстов и ранних филологических источников, найти тот, который мог повлечь за собой перестройку грамматико-семантической системы позиционных глаголов. Как мне кажется,

${ }^{9}$ «En presence de morphemes identiques pourvus de sens differents, on doit se demander s'il existe un emploi ou ces deux sens recouvrent leur unite» [Benveniste 1954: 251]. 
таким контекстом стал императив. Вместе с тем нельзя, конечно же, выпускать из виду наличие паронимической аттракции, возникшей между глаголом положения в пространстве ester и глаголом существования estre. Результатом этой аттракции стало постепенное ослабление глагола ester и его семантическое сближение с глаголом estre, в результате которого причастные формы étant и été перешли к глаголу 'быть', а сам он был вытеснен из употребления, оставшись лишь в составе нескольких юридических формул.

Таким образом, можно сказать, что конкурентные отношения между предикатом être en son estant и синонимичным ему неологизмом être debout, возникшие в XIV в., продолжались примерно до середины XVI в. Усиление позиций предикатов être <se tenir > debout стало возможным благодаря грамматико-семантическому фактору: императив Debout, получивший распространение в XVI в., позволил аккумулировать представление о движении вверх, о переходе от горизонтального положения к вертикальному, и одновременно — от пассивного состояния к активному.

\section{Литература}

Аошуан Тань. Китайская картина мира. Язык, культура, ментальность. М. : Языки славянской культуры, 2004. 231 с.

Апресян Ю.Д. Основания системной лексикографии // Апресян В.Ю., Аnресян Ю. Д., Бабаева Е. Э., Богуславская О. Ю., Иомдин Б. Л., Крылова Т. В., Левонтина И.Б., Санников А. В., Урысон Е. В. Языковая картина мира и системная лексикография / отв. ред. Ю.Д. Апресян. М. : Языки славянских культур, 2006. С. 33-160.

Апресян Ю. Д. Трехуровневая теория управления: лексикографический аспект // Апресян Ю.Д., Богуславский И.М., Иомдин Л.Л., Санников В. 3. Теоретические проблемы русского синтаксиса. Взаимодействие грамматики и словаря / отв. ред. Ю. Д. Апресян. М. : Языки славянских культур, 2010. С. 281-380.

Бабаева Е.Э. Формирование семантической структуры слова простой в русском языке // Апресян В. Ю., Апресян Ю. Д., Бабаева Е. Э., Богуславская О. Ю., Иомдин Б.Л., Крылова Т.В., Левонтина И.Б., Санников А. В., Урысон Е.В. Языковая картина мира и системная лексикография / отв. ред. Ю.Д. Апресян. М. : Языки славянских культур, 2006. С. 761-845.

Гак В.Г. Функционально-семантическое поле предикатов локализации // Теория функциональной грамматики. Локативность. Бытийность. Посессивность. Обусловленность / отв. ред. А. В. Бондарко. СПб. : Наука, 1996. С. 6-26.

Дмитренко С. Ю., Храковский В. С. Глаголы стандартных и нестандартных положений в пространстве // Слово и язык. Сборник статей к 80-летию академика Ю.Д. Апресяна / отв. ред. И. М. Богуславский, Л.Л. Иомдин, Л. П. Крысин. М. : Языки славянских культур, 2011. С. 182-206.

Дмитренко С.Ю., Храковский В.С. Проблемы семантической и таксономической классификации предикатов (сопоставительный анализ глаголов, обозначающих стандартные и нестандартные положения тела человека) // Проблемы 
функциональной грамматики: Принцип естественной классификации / отв. ред. В. Казаковская. М. : Языки славянских культур, 2013. С. 149-192.

Кашкин E. В. Глаголы позиции и их переходные соответствия в ижемском диалекте коми-зырянского языка // Родной язык. 2016 a. № 1 (4). С. 54-76.

Кашкин E.B. Семантика хантыйских позиционных предикатов // Проблемы лексико-семантической типологии. Вып. 3 / под ред. А. А. Кретова. Воронеж : ВГУ, 2016б. С. 78-88.

$K o p d u$ E.E. Грамматика глаголов нестандартных положений и перехода в нестандартные положения тела во французском языке: семантическая группа s'appuyer 'опираться' // Acta Linguistica Petropolitana. Труды Института лингвистических исследований. 2014. Т. 10. № 3. С. 341-364.

Корди E.E. Грамматика позиционных глаголов во французском языке (семантическая группа глаголов наклона) // Acta Linguistica Petropolitana. Труды Института лингвистических исследований. 2015. Т. 11. № 1. С. 757-783.

$K о р \partial u$ E. E. Глаголы стандартного положения в пространстве тела человека во французском языке // Известия РАН. Серия литературы и языка. 2016. № 1. С. 40-50.

Кюсева М.В., Рыжова Д.А. 'Сидеть', 'стоять', 'лежать': локативная предикация в кабардино-черкесском языке // Проблемы лексико-семантической типологии. Вып. 2 / под ред. А. А. Кретова. Воронеж : ВГУ, 2013. С. 253-275.

Майсак T.A. Типология грамматикализации конструкций с глаголами движения и глаголами позиции. М. : Языки славянских культур, 2005. 480 с.

Рахилина E.B. Семантика русских «позиционных» предикатов: cmoяmь, лежать, сидеть и висеть // Вопросы языкознания. 1998. № 6. С. 69-80.

Рахилина Е. В., Лемменс М. Русистика и типология: лексическая семантика глаголов со значением 'сидеть' в русском и нидерландском // Russian linguistics. 2003. № 27 (3). Р. 313-328.

Cтоянова E. A. Глаголы положения в пространстве в норвежском языке: дис. ... канд. филол. наук / Санкт-Петерб. гос. ун-т. СПб., 2013. 173 с.

Топоров В. Н. Об одном из парадоксов движения. Несколько замечаний о сверхэмпирическом смысле глагола «стоять», преимущественно в специализированных текстах // Концепт движения в языке и культуре / отв. ред. Т. А. Агапкина. М. : Индрик, 1996. С. 7-89.

Топоров В. Н. Из индоевропейской этимологии IV // Топоров В. Н. Исследования по этимологии и семантике. Т. 2 : Индоевропейские языки и индоевропеистика. Кн. 1. М. : Языки славянских культур, 2006. С. 123-154.

Ameka, Levinson 2007 - The Typology and Semantics of Locative Predication: Posturals, Positionals and Other Beasts / ed. by F. K. Ameka, S. C. Levinson // Linguistics. 2007. Vol. 45. № 5/6. P. 847-871.

Benveniste E. Problèmes Sémantiques de la Reconstruction // WORD. 1954. № 2-3 (10). P. 251-264.

DAF — Le Dictionnaire de l'Académie françoise. Vols. 1-2. Paris : Chez la Veuve de Jean Baptist Coignard, 1694. 
DMF — Dictionnaire du Moyen français [Электронный pecypc]. URL: http://www. atilf.fr/dmf

Estienne $R$. Dictionnaire françois-latin, contenant les motz et les manières de parler françois, tournez en latin. Paris : R. Etienne, 1539. 539 p.

Estienne R. Dictionnarium latinogallicum. 1552 [Электронный ресурс]. URL: https://fr.wikisource.org/wiki/Dictionarium_latinogallicum___Robert_Estienne,_1552

FEW — von Wartburg $W$. Französisches Etymologisches Wörterbuch [Электронный pecypc]. URL: http://www.atilf.fr

Furetière A. Dictionnaire universel, contenant généralement tous les mots françois tant vieux que modernes, et les termes de toutes les sciences et des arts. T. 1-3. La Haye : A. et R. Leers, 1690 [Электронный ресурс]. URL: https://gallica.bnf.fr/ark:/12148/bpt6k50614b.image

Grinevald C. Vers une typologie de l'expression de la localisation statique: le cas des prédicats locatifs // Linguistique typologique / eds. G. Lazard, C. Moyse-Faurie. Paris : Presses universitaires, 2005. S. 33-54.

Hansen E. Stä, sidde, ligge // Mai og masle. 1974. T. 1. №2. S. 26-32.

IGW - Köbler G. Indogermanisches Wörterbuch. [Электронный ресурс]. URL: http://www.proto-indo-european.ru/dic-kobler/index.html

Jakobsson U. Familjelika betydelser hos STÄ, SITTA och LIGGA. En analys ur den kognitiva semantikens perspektiv. Lund : Institutionen för nordiska spräk, 1996. 66 p.

Kuteva T. On "sit"/"stand"/"lie" auxiliation // Linguistics. 1999. Vol. 37 (2). S. 191213.

Lakoff G., Johnson M. Metaphors we live by. London : The University of Chicago Press, 2003. $276 \mathrm{p}$.

Monet $P h$. Invantaire de deux langues francoise et latine. Lyon : Veuve Rigaud, 1635. $990 \mathrm{p}$.

Newman 2002 - The Linguistics of Sitting, Standing and Lying / ed. by J. Newman. Amsterdam; Philadelphia : John Benjamins, 2002. 407 p.

Nicot $J$. Thresor de la langue francoyse tant ancienne que moderne. Paris : D. Douceur, 1606. $192 \mathrm{p}$.

Oudin C. Thresor des deux langues francoise et espagnolle. Paris : Chez Marc Orry, 1575. $687 \mathrm{p}$.

Palsgrave J. L'éclaircissement de la langue française. Texte anglais original avec traduction et notes de Susan Baddeley. Paris : Honoré Champion, 2003. 775 p.

Pomey F. A. Dictionnaire royal augmenté, seconde édition, enrichie d'un grand nombre d'expressions élégantes, de quantité de mots françois nouvellement introduits, des termes des arts et de cinquante descriptions, comme aussi d'un petit traité de la vénerie et de la fauconnerie. Lyon : Chez Antoine Molin, 1671. 1024-1064 p.

Serra Borneto C. Liegen and stehen in German: A study in horizontality and verticality // Cognitive Linguistics in the Redwoods: The Expansion of a New Paradigm in Linguistics / ed. by E. H. Casad. Berlin ; New York : Mouton de Gruyter, 1996. P. 459-505.

Tadmor U., Haspelmath M., Taylor B. Borrowability and the notion of basic vocabulary // Diachronica. 2010. №2 (27). P. 226-246. 
Thomasson Lt-C de. Les curiosités de la langue française. Paris : Librairie Larousse, 1938. 284 p.

Van der Toorn M. C. Over de semantische kenmerken van staan, liggen en zitten' // De Nieuwe Taalgids. 1972. № 6. S. 459-464.

Van Oosten J. Sitting, standing, and lying in Dutch: A cognitive approach to the distribution of the verbs zitten, staan, and liggen // Dutch Linguistics at Berkeley / ed. by J. Van Oosten, J.P. Snapper. Berkeley : Dutch Studies Program, University of California at Berkeley, 1982. P. 137-160.

\author{
E. E. Babayeva \\ Lomonosov Moscow State University \\ (Russia, Moscow) \\ llevidova@gmail.com
}

\title{
ON ONE PARTICULAR FEATURE OF THE SYSTEM OF PREDICATES OF POSITION IN SPACE IN FRENCH
}

In the article on the basis of the analysis of French philological sources of the $16^{\text {th }}$ $17^{\text {th }}$ centuries the hypothesis is offered concerning contextual conditions of appearance and fixation of the predicate être debout in the system of positional verbs of the French language, and also concerning chronology of this process. Position verbs ('stand,' 'sit,' 'lie'), which prototypically indicate a person's position, are distinguished within a wider group of location predicate. Position verbs are included in the 200-word Swadesh list, which brings together units belonging to the most stable basic vocabulary of the language. In Romance languages, the meaning of 'standing' can be conveyed in several ways, for example by the verb stare, which eventually ascends to i.-e. *st $\bar{\alpha}-$ : stă- (it. stare, romanian sta) as well as a number of word combinations, for example: 'stand on your feet' (it. stare in piedi, spanish estar di pie, port. estar de pié, romanian sta pe picioare), 'be on your feet' (it. essere in piedi, it. rimanere in piedi, port. ficar de pé), 'be straight' (it. essere ritto, catalan estar dret). The peculiarity of the French language is to convey the meaning of 'stand' by means of the predicate être debout, which displaced the ancient verb ester. The article suggests a hypothesis according to which the être debout predicate, formed in the $14^{\text {th }}$ century, became particularly popular in the $16^{\text {th }}$ century. When interpreting this process, one cannot ignore the fact of the paronymic attraction between the positional verb ester and the verb of existence estre, which caused great inconveniences. However, the strengthening of the position of the predicate etre debout was probably made possible by a grammatical and semantic factor: the imperative Debout, which at that time was probably an innovation, allowed to accumulate the idea of the transition from a horizontal position to a vertical one and at the same time from a passive state to an active one, which led to the fixation of this very predicate in the system of positional verbs. 
Keywords: historical semantics, history of lexicography, history of concepts, history of vocabulary, functional grammar.

\section{References}

Ameka F. K., Levinson S. C. (Eds.). The Typology and Semantics of Locative Predication: Posturals, Positionals and Other Beasts.. Linguistics, 2007, vol. 45, no. 5/6, pp. 847-871. / ed. by F. K. Ameka, S. C. Levinson / Linguistics 45 (5/6). Berlin : Mouton de Gruyter, 2007. P. 847-871.Berlin, Mouton de Gruyter, 2007.

Aoshuan Tan'. Kitaiskaya kartina mira. Yazyk, kul'tura, mental'nost' [The Chinese worldview. Language, culture, mentality]. Moscow, Yazyki slavyanskoi kul'tury Publ., 2004. 231 p. (In Russ.)

Apresyan Yu.D. [The Basis of system lexicography]. V.Yu. Apresyan, Yu.D. Apresyan, E. E. Babaeva, O.Yu. Boguslavskaya, B. L. Iomdin, T.V. Krylova, I.B. Levontina, A. V. Sannikov, E. V. Uryson, Yazykovaya kartina mira i sistemnaya leksikografiya [Language worldview and system lexicography]. Yu.D. Apresyan (Ed.). Moscow, Yazyki slavyanskikh kul'tur Publ., 2006, pp. 33-160. (In Russ.)

Apresyan Yu.D. [Three-level theory of subordination: lexicographical aspect]. Yu.D. Apresyan, I. M. Boguslavskii, L. L. Iomdin, V.Z. Sannikov, Teoreticheskie problemy russkogo sintaksisa. Vzaimodeistvie grammatiki i slovarya [Theoretical problems of Russian syntax. The Interaction of grammar and dictionary]. Yu. D. Apresyan (Ed.). Moscow, Yazyki slavyanskikh kul'tur Publ., 2010, pp. 281380. (In Russ.)

Babaeva E. E. [Formation of semantic structure of a word prostoi 'simple' in Russian]. V.Yu. Apresyan, Yu.D. Apresyan, E.E. Babaeva, O.Yu. Boguslavskaya, B.L. Iomdin, T.V. Krylova, I.B. Levontina, A.V. Sannikov, E. V. Uryson, Yazykovaya kartina mira i sistemnaya leksikografiya [Language worldview and system lexicography]. Yu. D. Apresyan (Ed.). Moscow, Yazyki slavyanskikh kul'tur Publ., 2006, pp. 761-845. (In Russ.)

Benveniste E. Problèmes Sémantiques de la Reconstruction. WORD, 1954, no. 2-3(10), pp. 251-264.

Dictionnaire du Moyen français. Available at: http://www.atilf.fr/dmf (accessed 10.12.2019)

Dmitrenko S.Yu., Khrakovskii V.S. [The Problems of semantic and taxonomic classification of predicates (a comparative analysis of verbs denoting standard and non-standard positions of the human body)]. Problemy funktsional'noi grammatiki: Printsip estestvennoi klassifikatsii [The Problems of functional grammar: The principle of natural classification]. V. Kazakovskaya (Ed.). Moscow, Yazyki slavyanskikh kul'tur Publ., 2013, pp. 149-192. (In Russ.)

Dmitrenko S.Yu., Khrakovskii V. S. [Verbs of standard and non-standard positions in space]. Slovo i yazyk. Sbornik statei k 80-letiyu akademika Yu.D.Apresyana [Word and language. A collection of articles on the $80^{\text {th }}$ Anniversary of Academician Y.D. Apresyan]. I. M. Boguslavskii, L. L. Iomdin, L. P. Krysin (Eds.). Moscow, Yazyki slavyanskikh kul'tur Publ., 2011, pp. 182-206. (In Russ.) 
Estienne R. Dictionnaire françois-latin, contenant les motz et les manières de parler françois, tournez en latin. Paris, R. Etienne, 1539.523 p.

Estienne R. Dictionnarium latinogallicum. Available at: https://fr.wikisource.org/ wiki/Dictionarium_latinogallicum_-_Robert_Estienne,_1552 (accessed 10.12.2019)

Furetière A. Dictionnaire universel, contenant généralement tous les mots françois tant vieux que modernes, et les termes de toutes les sciences et des arts. La Haye, A. et R. Leers. Vols. 1-3. Available at: https://gallica.bnf.fr/ark:/12148/bpt6k50614b.image (accessed 10.12.2019)

Gak V.G. [The Functional-semantic field of localization predicates] // Teoriya funktsional'noi grammatiki. Lokativnost'. Bytiinost'. Posessivnost'. Obuslovlennost' [Theory of functional grammar. Locativity. Beingness. Possessiveness. Conditionality]. A. V. Bondarko (Ed.). St Petersburg, Nauka Publ., 1996, pp. 6-26. (In Russ.)

Grinevald C. Vers une typologie de l'expression de la localisation statique: le cas des prédicats locatifs. Linguistique typologique. G. Lazard, C. Moyse-Faurie (Eds.). Paris, Presses universitaires, 2005, pp. 33-54.

Hansen E. Stä, sidde, ligge [To stand, to sit, to lie]. Mai og masle, 1974, no. 1(2), pp. 26-32. (In Dutch)

Jakobsson U. Familjelika betydelser hos STÄ, SITTA och LIGGA. En analys ur den kognitiva semantikens perspektiv [Family-like meanings of standing, sitting and lying. An analysis from the perspective of cognitive semantics]. Lund, Institutionen för nordiska spräk, 1996. 66 p. (In Swedish)

Kashkin E. V. [Verb position in the Ishamic dialect of the Komi-Zyrian language]. Rodnoi yazyk, 2016a, no. 1(4), pp. 54-76. (In Russ.)

Kashkin, E. V. [Semantics of Khanty position predicates]. Problemy leksiko-semanticheskoi tipologii. Vyp. 3 [Problems of lexical and semantic typology. Vol. 3]. A. A. Kretov (Ed.). Voronezh, Voronezh St. Univ. Publ., 2016b, pp. 78-88. (In Russ.)

Köbler G. Indogermanisches Wörterbuch. Available at: http://www.proto-indo-european.ru/dic-kobler/index.html (accessed 10.12.2019)

Kordi E. E. [Grammar of positional verbs in French (a semantic group of inclination)]. Acta Linguistica Petropolitana, 2015, vol. 11, no. 1, pp. 757-783. (In Russ.)

Kordi E.E. [The Grammar of verbs in non-standard positions and the transitions to non-standard body positions in French: semantic group s'appuyer 'lean']. Acta Linguistica Petropolitana, 2014, vol. 10, no. 3, pp. 341-364. (In Russ.)

Kordi E.E. [Verbs in standard position in human space in French]. Izvestiya RAN. Seriya literatury i yazyka, 2016, no. 1, pp. 40-50. (In Russ.)

Kuteva T. On "sit"/"stand"/“lie" auxiliation. Linguistics, 1999, no. 2(37), pp. 191-213.

Kyuseva M. V., Ryzhova D. A. ['Sit', 'stand', 'lie': local predication in the KabardinoCircassian language]. Problemy leksiko-semanticheskoi tipologii. Vyp. 2 [Problems of lexical and semantic typology. Vol. 2]. A. A. Kretov (Ed.). Voronezh, Voronezh St. Univ. Publ., 2013, pp. 253-275. (In Russ.)

Lakoff G., Johnson M. Metaphors we live by. London, The University of Chicago Press, 2003. $276 \mathrm{p}$. 
Le Dictionnaire de l'Académie françoise. Paris, Chez la Veuve de Jean Baptiste Coignard, 1694. Vols. 1-2.

Maisak T.A. Tipologiya grammatikalizatsii konstruktsii $s$ glagolami dvizheniya i glagolami pozitsii [The Typology of grammaticalization of structures with verbs of motion and verbs of position]. Moscow, Yazyki slavyanskikh kul'tur Publ., 2005. 480 p. (In Russ.)

Monet Ph. Invantaire de deux langues francoise et latine. Lyon, Veuve Rigaud, 1635. $990 \mathrm{p}$.

Nicot J. Thresor de la langue francoyse tant ancienne que moderne. Paris, D. Douceur, 1606. $192 \mathrm{p}$.

Oudin C. Thresor des deux langues francoise et espagnolle. Paris, Chez Marc Orry, $1575.687 \mathrm{p}$.

Palsgrave J. L'éclaircissement de la langue française. Texte anglais original avec traduction et notes de Susan Baddeley. Paris, Honoré Champion, 2003. 775 p.

Pomey F. A. Dictionnaire royal augmenté, seconde édition, enrichie d'un grand nombre d'expressions élégantes, de quantité de mots françois nouvellement introduits, des termes des arts et de cinquante descriptions, comme aussi d'un petit traité de la vénerie et de la fauconnerie. Lyon, Chez Antoine Molin, 1671. 1024-10-64 p.

Rakhilina E.V. [The Semantics of Russian positional predicates : stoyat', lezhat', sidet' i viset']. Voprosy yazykoznaniya, 1998, no. 6, pp. 69-80. (In Russ.)

Rakhilina E. V., Lemmens M. [Russian Linguistics and Typology: the lexical semantics of verbs with the meaning 'to sit' in Russian and Dutch]. Russian linguistics, 2003, no. 27(3), pp. 313-328. (In Russ.)

Serra Borneto C. Liegen and stehen in German: A study in horizontality and verticality. Cognitive Linguistics in the Redwoods: The Expansion of a New Paradigm in Linguistics. E. H. Casad (Ed.). Berlin, New York, Mouton de Gruyter, 1996, pp. 459-505.

Stoyanova E. A. Glagoly polozheniya v prostranstve v norvezhskom yazyke [Verbs of position in space in Norwegian. Cand. philol. sci. diss]. St Petersburg, 2013. 173 p. (In Russ.)

Tadmor U., Haspelmath M., Taylor B. Borrowability and the notion of basic vocabulary. Diachronica, 2010, no. 2(27), pp. 226-246.

The Linguistics of Sitting, Standing and Lying. J. Newman (Ed.). Amsterdam, Philadelphia, John Benjamins, 2002. 407 p.

Thomasson Lt-C. de. Les curiosités de la langue française. Paris, Librairie Larousse, 1938. $284 \mathrm{p}$.

Toporov V.N. [About one of the paradoxes of motion. A few remarks about the super-empirical sense of the verb 'to stand', mainly in specialized texts]. Kontsept dvizheniya v yazyke i kul'ture [Concept of movement in language and culture]. T. A. Agapkina (Ed.). Moscow, Indrik Publ, 1996, pp. 7-89. (In Russ.)

Toporov V.N. [From Indo-European etymology IV-4]. V.N. Toporov. Issledovaniya po etimologii i semantike. T. om 2.: Indoevropeiskie yazyki i indoevropeistika. Kniga. 1 [Researches on etymology and semantics. Vol. 2: Indo-European languages 
and Indo-European studies. Iss. 1]. Moscow, Yazyki slavyanskikh kul'tur Publ., 2006, pp. 123-154. (In Russ.)

Van der Toorn M.C. Over de semantische kenmerken vanstaan, liggen en zitten' [About the semantic characteristics of standing, lying and sitting']. De Nieuwe Taalgids, 1972, no. 6, pp. 459-464. (In Dutch)

Van Oosten J. Sitting, standing, and lying in Dutch: A cognitive approach to the distribution of the verbs zitten, staan, and liggen. Dutch Linguistics at Berkeley. J. Van Oosten, J.P. Snapper (Eds.). Berkeley, Dutch Studies Program, University of California at Berkeley, 1982, pp. 137-160.

Wartburg W. von. Französisches Etymologisches Wörterbuch. Available at: http:// www.atilf.fr (accessed 10.12.2019) 